TITLE:

\title{
Determination of local phase velocity by intercomparison of seismograms from strain and pendulum instruments
}

\author{
$\operatorname{AUTHOR}(\mathrm{S})$ : \\ Mikumo, Takeshi; Aki, Keiiti
}

\section{CITATION:}

Mikumo, Takeshi ... [et al]. Determination of local phase velocity by intercomparison of seismograms from strain and pendulum instruments. Journal of Geophysical Research 1964, 69(4): 721-731

\section{ISSUE DATE:}

1964-02-15

URL:

http://hdl.handle.net/2433/193374

RIGHT:

Copyright 1964 by the American Geophysical Union. 


\title{
Determination of Local Phase Velocity by Intercomparison of Seismograms from Strain and Pendulum Instruments ${ }^{1}$
}

\author{
Takeshi Mikumo ${ }^{2}$ and KeIrTi AKI ${ }^{3}$ \\ Seismological Laboratory \\ California Institute of Technology, Pasadena
}

\begin{abstract}
An attempt was made to determine the local phase velocity of seismic waves by a combined analysis of records obtained by the strain and pendulum seismographs set up at a single station. The record of a strain seismograph may be reducible to the space derivaative of the ground displacement with respect to the direction of a strain rod, and the time derivative of the same displacement may be obtained from a pendulum record. The ratio of the two derivatives should then be the apparent local phase velocity of the waves along the direction of the instruments. An amplitude and phase compensation technique was applied to the two kinds of seismograms over an appropriate frequency range in order to get the phase velocities of seismic waves for five earthquakes recorded at Pasadena. The results obtained by this method show good agreement with the theoretically predicted velocities for body waves and, in some cases, for surface waves. This suggests that the present method may be useful for the identification of many unknown phases, especially of body waves and highermode surface waves. It is expected that much better results could be obtained from a system of two-component pendulums and strain seismometers especially designed and calibrated for this purpose.
\end{abstract}

Introduction. As is well known, the response of a strain seismograph to ground displacement differs from that of a pendulum seismograph in their directional characteristics, and the former depends on the phase velocity of the waves while the latter does not [Benioff, 1935]. A comparison of seismograms from the two instruments would therefore provide some information which cannot be obtained from either instrument alone [Benioff and Gutenberg, 1952].

The record of the strain seismograph may be reducible to the space derivative of the ground displacement with respect to the direction of the strain rod, $\partial u / \partial x$, whereas the time derivative of the same displacement, $\partial u / \partial t$, may be obtained from the pendulum record. The ratio of the latter derivative to the former should, then, give the apparent local phase velocity of the waves along the direction of the strain rod. That is, $c_{\nexists}=(\partial u / \partial t) /(\partial u / \partial x)$. The true phase velocity and direction of approach of the waves could in

1 Contribution 1207, Division of Geological Sciences, California Institute of Technology, Pasadena.

2 On leave from Disaster Prevention Research Institute, Kyoto University, Kyoto, Japan.

${ }^{3}$ On leave from Earthquake Research Institute, Tokyo University, Tokyo, Japan. principle be determined if there were two horizontal components, perpendicular to each other, of the respective seismographs.

The phase velocity, on the other hand, can be determined from a direct time delay measurement for the well-dispersed wave train [Press, 1956; Brune et al., 1960] and also by the Fourier phase-spectrum method which was successfully applied to the less dispersed waves such as $G$ waves [Satô, 1958; Toksöz and Ben-Menahem, 1963]. The seismometer array, of which a tripartite. net is the simplest, has often been used to measure the local value of phase velocities. It would be rather difficult, however, to apply these methods to a long train composed of many kinds of waves, including body waves, unless the corresponding waves are clearly identified at more than two stations.

An advantage of the present method is that it enables us to determine the phase velocity of seismic waves from the amplitudes, instead of the time delays, recorded by the two kinds of seismographs set up at a single station. This serves to identify various phases over an entire seismogram, an objective which may easily be attained by the rapid automatic computation technique to be described.

Technique. The technique of obtaining the 
phase velocity from the strain and pendulum records is now described.

Let $u(t)$ be the horizontal ground displacement of a linearly polarized wave with a phase velocity $c$, let $u_{1}(t)$ be the component of $u(t)$ along the direction of a strain rod, and let $u_{s}(t)$ be the total strain or relative displacement of piers at a distance of $L$. Then we have $u_{1}(t)=$ $p(\alpha) u(t)$ and $u_{2}(t)=\int_{0}^{L} p(\alpha)(\partial u / \partial x) d x$, where $\alpha$ is the angle between the rod and the direction of propagation of waves, $p(\alpha)$ takes a value of $\cos \alpha$ for the apparent longitudinal waves and $-\sin \alpha$ for the apparent transverse waves. $u_{2}(t)$ can be rewritten in the following form by using the relation $\partial u / \partial x=-(\cos \alpha / c) \partial u / \partial t$ :

$$
u_{2}(t)=\frac{L}{c} s(\alpha) \frac{\partial u}{\partial t} \quad s(\alpha)=-p(\alpha) \cos \alpha
$$

[Benioff, 1935]. On the other hand, the relation between $u_{i}(t)$ and its Fourier transform $U_{i}(\omega)$ is expressed by the formulas,

and

$$
u_{i}(t)=\frac{1}{2 \pi} \int_{-\infty}^{\infty} U_{i}(\omega) e^{i \omega t} d \omega
$$

$$
U_{i}(\omega)=\int_{-\infty}^{\infty} u_{i}(t) e^{-i \omega t} d t
$$

The pendulum and strain records, $f_{p}(t)$ and $f_{\text {. }}(t)$, can be expressed by the following equations, if their Fourier transforms are denoted by $F_{p}(\omega)$ and $F_{0}(\omega)$ and if the frequency response functions of the two seismographs to the ground displacement are $R_{p}(\omega)$ and $R_{f}(\omega)$ and that of the strain seismograph to the ground velocity is $R^{\prime},(\omega)$ :

$$
\begin{aligned}
f_{D}(t) & =\frac{1}{2 \pi} \int_{-\infty}^{\infty} F_{p}(\omega) e^{i \omega t} d \omega \\
& =\frac{1}{2 \pi} \int_{-\infty}^{\infty} R_{p}(\omega) U_{1}(\omega) e^{i \omega t} d \omega \\
& =K_{p} p(\alpha) \cdot \frac{1}{2 \pi} \int_{-\infty}^{\infty} \hat{R}_{p}(\omega) e^{i \varphi_{p}(\omega)} U(\omega) e^{i \omega t} d \omega
\end{aligned}
$$

$$
\begin{aligned}
f_{\bullet}(t) & =\frac{1}{2 \pi} \int_{-\infty}^{\infty} F_{\bullet}(\omega) e^{i \omega t} d \omega \\
& =\frac{1}{2 \pi} \int_{-\infty}^{\infty} R_{\bullet}^{\prime}(\omega) U_{2}(\omega) e^{i \omega t} d \omega \\
& =K_{\&} \&(\alpha) \frac{L}{c} \cdot \frac{1}{2 \pi} \int_{-\infty}^{\infty} \hat{R}_{\Delta}(\omega) e^{i \varphi_{0}(\omega)} U(\omega) e^{i \omega t} d \omega
\end{aligned}
$$

since $R_{p}(\omega)=K_{p} \hat{R}_{p}(\omega) e^{i \varphi_{p}(\omega)}, R_{s}^{\prime}(\omega)=$ $-i R_{s}(\omega) / \omega$, and $R_{z}(\omega)=K_{8} \hat{R}_{s}(\omega) e^{i \varphi_{s}(\omega)}$, where $\hat{R}_{p, 8}(\omega)$ and $\varphi_{p, e}(\omega)$ are the amplitude and phase spectrums, and $K_{p, \text {, the instrumental }}$ constants, of the two seismograph systems, respectively. In the case of an electromagnetic pendulum seismograph and a strain seismagraph with a velocity transducer, the frequency responses are

$$
\left.\begin{array}{l}
\hat{R}_{p}(\omega)=\omega^{3} /\left\{[A(\omega)]^{2}+[B(\omega)]^{2}\right\}^{1 / 2} \\
\varphi_{p}(\omega)=\tan ^{-1}[-A(\omega) / B(\omega)]
\end{array}\right\}
$$

where

$$
\begin{aligned}
& A(\omega)=\left(\omega^{2}-\omega_{1}{ }^{2}\right)\left(\omega^{2}-\omega_{2}{ }^{2}\right) \\
& \quad-4 \epsilon_{1} \epsilon_{2}\left(1-\sigma^{2}\right) \omega^{2} \\
& B(\omega)=2 \omega\left[\epsilon_{1}\left(\omega^{2}-\omega_{2}{ }^{2}\right)+\epsilon_{2}\left(\omega^{2}-\omega_{1}{ }^{2}\right)\right]
\end{aligned}
$$

and

$$
\left.\begin{array}{l}
\hat{R}_{s}(\omega)=\omega^{2} /\left\{[C(\omega)]^{2}+[D(\omega)]^{2}\right\}^{1 / 2} \\
\varphi_{s}(\omega)=\tan ^{-1}[D(\omega) / C(\omega)]
\end{array}\right\}
$$

where

$$
\begin{aligned}
& C(\omega)=\omega^{2}-{\omega_{2}}^{2} \\
& D(\omega)=2 \epsilon_{2}{ }^{\prime} \omega
\end{aligned}
$$

In equations 3 and $4, \omega_{1}, \omega_{2}$, and $\omega_{2}^{\prime}$ are the natural frequencies of the pendulum, of the connected galvanometer, and of the galvanometer connected to the strain seismograph, respectively; $\epsilon_{1}, \epsilon_{2}$, and $\epsilon_{2}^{\prime}$ are the corresponding damping coefficients, and $\sigma^{2}$ is the coupling constant.

Figure 1 shows the theoretical amplitude response curves for the Benioff long-period seismograph $\left(T_{1}=1 \mathrm{sec}, T_{2}=90 \mathrm{sec}\right)$ and for the Benioff strain seismograph with a 75-sec galvanometer. The corresponding phase response curves are shown in Figure 2. It is to be noted that the phase delay of the strain seismograph should be zero for the infinite frequency, if we take a value of $\pi / 2$ for the corresponding delay for the pendulum seismograph.

To obtain the phase velocity from the strain and pendulum records it is not always necessary to compute the space and time derivatives of the true ground displacement. In the present case, the ground displacements, instead of these derivatives, are computed from the respective seismograms. The method of amplitude and phase equalization, which was first introduced 


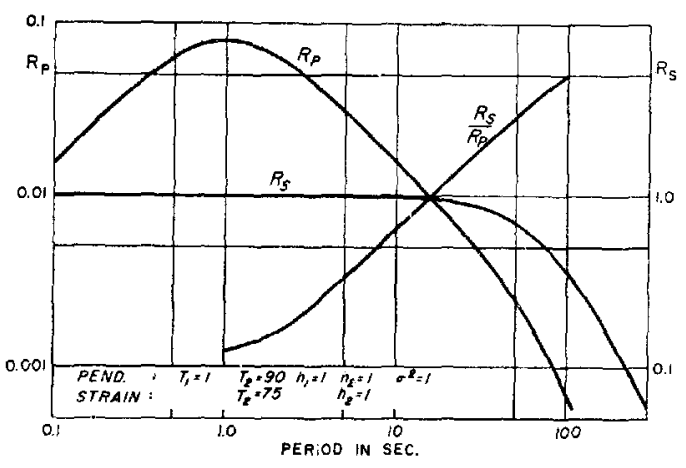

Fig. 1. Amplitude response curves of Benioff strain and pendulum seismographs.

by Tukey [1959] and later developed by $A k i$ [1960], was used for this purpose. We shall first compute the following time function from the frequency response of the instruments:

$$
r_{p, e}(t)=\int_{Q} R_{p, *^{*}}(\omega) e^{i \omega t} d \omega
$$

where

$$
\boldsymbol{R}_{\nu_{*} *}{ }^{*}(\omega)=e^{-i \varphi_{p, \ell(\varphi)}} / \hat{R}_{p, *}(\omega)
$$

The function $r_{p, s}(t)$ is a compensator which restores the ground displacement over a certain frequency range $\Omega$ by compensating for the distortion in the amplitude and phase that is introduced by the seismographs.

The next step is to convolve this function with the original seismogram. The ground displacement can be obtained from the pendulum record by this procedure as follows:

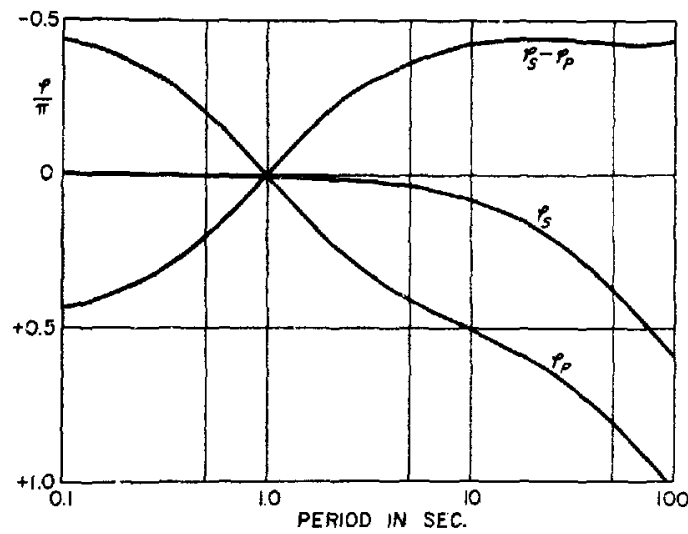

Fig. 2. Phase response curves of Benioff strain and pendulum seismographs.

$$
u(\tau)=\frac{1}{K_{p} p(\alpha)} \int r_{p}(t) f_{p}(t+\tau) d t
$$

Likewise, a similar equation should be obtained from the strain record, if the phase velocity can be assumed to be constant without respect to frequency, at a certain time range

$$
u(\tau)=\frac{c / L}{K_{s} \varepsilon(\alpha)} \int r_{s}(t) f_{s}(t+\tau) d t
$$

Equating the two expressions given above, we get the apparent phase velocity,

$$
\frac{c(\tau)}{\cos \alpha}=L \frac{K_{s}}{K_{p}} \frac{\int r_{p}(t) f_{p}(t+\tau) d t}{\int r_{s}(t) f_{s}(t+\tau) d t} \equiv K \frac{\hat{f}_{p}(\tau)}{\hat{f}_{s}(\tau)}
$$

The mean phase velocity over a time interval between $t_{1}$ and $t_{2}$ may be defined by

$$
\frac{\langle c\rangle}{\cos \alpha}=K \frac{\frac{1}{t_{2}-t_{1}} \int_{t_{1}}^{t_{s}}\left|\hat{f}_{p}(\tau)\right| d \tau}{\frac{1}{t_{2}-t_{1}} \int_{t_{1}}^{t_{t}}\left|\hat{f}_{s}(\tau)\right| d \tau}
$$

which indicates that the mean velocity can be obtained from the mean absolute amplitudes on peridulum and strain records over the time interval.

The compensation function $r_{p, s}(t)$ was cornputed by the following approximation [ $A k i$, $1960]$, under the condition that $\left|R_{p, s}{ }^{*}(\omega)\right|=1 /$ $\hat{R}_{p, s}(\omega)$ when $\omega_{1}<\omega<\omega_{2}$ and otherwise it is zero,

$$
\begin{aligned}
r_{p, s}(t) & =2 \int_{\omega_{1}}^{\omega_{z}}\left|R_{p, s} *(\omega)\right| \\
& \cdot \cos \left[\omega t-\varphi_{p, s}(\omega)\right] d \omega \\
= & 2 \sum_{i} \int_{\omega_{i}-\Delta \omega_{i} / 2}^{\omega_{i}+\Delta \omega_{i} / 2}\left|R_{p, s} *(\omega)\right| \\
& \cdot \cos \left[\omega t-\varphi_{p, s}(\omega)\right] d \omega \\
\approx & 2 \sum_{i}\left|R_{p, s} *\left(\omega_{i}\right)\right| \Delta \omega_{i} \frac{\sin \left(\Delta \omega_{i}\left(t-t_{i}\right) / 2\right)}{\Delta \omega_{i}\left(t-t_{i}\right) / 2} \\
& \cdot \cos \left(\omega_{i} t-\omega_{i} \tau_{p, s i}\right)
\end{aligned}
$$

where $\tau_{p, s i}=\varphi_{p, s}\left(\omega_{i}\right) / \omega_{i}$ and $t_{t}=\left(\partial_{p_{p, s} / \partial_{\omega}}\right)_{i}$. In our computer program the second-order correction was made to (10), following Dr. Harkrider's program. 


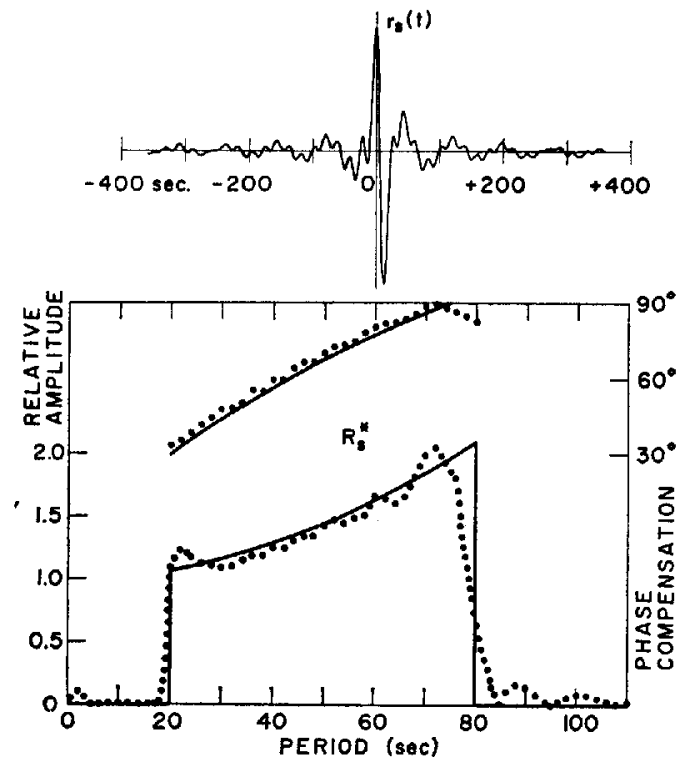

Fig. 3. Response of digital filter and compensation function applied to the strain record.

Figure 3 shows an example of the theoretical values of $R^{*}(\omega)$ and the compensation function $r_{c}(t)$, and Figure 4 of $R_{p}^{*}(\omega)$ and $r_{p}(t)$. The cross-correlation process works as a low-pass filter to cut off the waves with frequencies higher than $\omega_{2}$ and as a high-pass filter for frequencies lower than $\omega_{1}$. In the examples given above, 30 frequency bands were used between

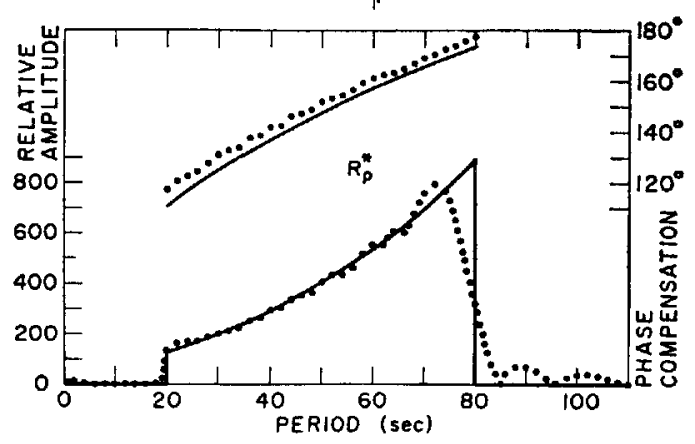

Fig. 4. Response of digital filter and compensation function applied to the pendulum method. $\omega_{1}=0.0785$ radian $(80 \mathrm{sec})$ and $\omega_{2}=0.3142$ radian $(20 \mathrm{sec})$. The time integration was carried out using 361 points spaced at 2 -sec intervals. A finite time length of the compensator carries systematic errors in the integration. For the purpose of examining the effect of the errors, the compensation function with the same time length as adopted in its application to the actual records was operated on purely sinusoidal waves with various frequencies by using a computing program designed by Dr. M. Shimshoni. The results are shown by dots in Figures 3 and 4 , in comparison with the theoretical responses. The errors will be corrected in the subsequent computation of mean amplitudes. The compensated seismogram will be given in the next section. These computations were done by an IBM 7090 computer at the California Institute of Technology, using a program which was designed in such a way that the constants of the seismographs and the degree of approximation could be introduced arbitrarily.

To estimate the absolute value of phase velocity, we must know the coefficients included in equation 8 or $9 . K_{p}$ for an electromagnetic seismograph and $K$, for a strain seismograph are [Mikumo, 1963]

$$
K_{p}=\frac{4 \pi^{2} G_{p}}{S_{p} T_{2}^{2} Z_{p} / \mu_{p}} \quad K_{s}=\frac{4 \pi^{2} G_{s}}{S_{s} T_{2}^{\prime 2} Z_{s} / \mu_{s}}
$$

where $G_{p}$ and $G$, are the voltage sensitivities of the seismograph transducers, $S_{p}$ and $S_{s}$ are the current sensitivities of the galvanometers, $T_{3}$ and $T_{2}^{\prime}$ are the free periods of the galvanometers, $Z_{p}$ and $Z_{s}$ are the circuit impedances, and $\mu_{p}$ and $\mu_{s}$ are the attenuation factors in the circuit. In the Benioff seismograph systems at the Seismological Laboratory in Pasadena, the rough values of these constants are $T_{2}=90 \mathrm{sec}$, $T_{2}^{\prime}=75 \mathrm{sec}, G_{p} \approx 7.2$ volts $\mathrm{sec} / \mathrm{cm}, G, \approx 12$ volts $\mathrm{sec} / \mathrm{cm}, S_{p} \approx 1 \times 10^{-10} \mathrm{amp} / \mathrm{mm}, S_{\approx} \approx$ $2 \times 10^{-10} \mathrm{amp} / \mathrm{mm}, Z_{p}=Z_{s}=1000 \mathrm{ohms}$, $\mu_{p}=\mu_{s}=1$, and $L=20 \mathrm{~m}$. With these values we get $K_{s} / K_{p} \approx 1.2$ and $K \approx 2.4 \times 10^{3} \mathrm{~cm} / \mathrm{sec}$. However, these constants are not known accurately enough to permit us to determine the absolute phase velocity. An alternative method will be adopted in the next section.

Analysis of seismogram. Table 1 summarizes five shocks used in the present analysis, with the date, origin time, location of epicenter, focal depth, magnitude, epicentral distance to Pasa- 
TABLE 1. List of Earthquakes

\begin{tabular}{|c|c|c|c|c|c|c|c|c|c|}
\hline \multirow[b]{2}{*}{ Shock } & \multirow[b]{2}{*}{ Date } & \multicolumn{2}{|c|}{$\begin{array}{c}\text { Origin } \\
\text { Time }\end{array}$} & \multicolumn{2}{|c|}{ Epicenter } & \multirow{2}{*}{$\begin{array}{c}\text { Focal } \\
\text { Depth, } \\
\text { km }\end{array}$} & \multirow{2}{*}{$\begin{array}{c}\text { Magni- } \\
\text { tude }\end{array}$} & \multirow{2}{*}{$\begin{array}{c}\text { Epicentral } \\
\text { Distance, } \\
\text { deg }\end{array}$} & \multirow{2}{*}{$\begin{array}{c}\text { Azimuth } \\
\text { deg }\end{array}$} \\
\hline & & $\mathrm{h} \mathrm{m}$ & $\mathrm{s}$ & $\lambda$ & $\varphi$ & & & & \\
\hline New Zealand & Sept. 6,1943 & 03411 & 15 & $158.0 \mathrm{E}$ & $55.1 \mathrm{~S}$ & Shallow & 7 & 113.7 & 218.6 \\
\hline Volcano Islands & May 30,1955 & 1231 & 41 & $142.5 \mathrm{E}$ & $24.5 \mathrm{~N}$ & 600 & $61 / 4$ & 83.8 & 297.0 \\
\hline Mexico & April 10,1957 & 05120 & 08 & $98.0 \mathrm{~W}$ & $15.5 \mathrm{~N}$ & Shallow & $61 / 4$ & 26.0 & 130.6 \\
\hline Japan & Jan. 22,1959 & 05102 & 25 & $142.3 \mathrm{E}$ & $37.9 \mathrm{~N}$ & 30 & $63 / 4$ & 76.7 & 306.3 \\
\hline Montana & Aug. 18,1959 & 0404 & 03 & $111.6 \mathrm{~W}$ & $44.9 \mathrm{~N}$ & Shallow & 6 & 11.8 & 23.4 \\
\hline
\end{tabular}

Range of digital filter applied to each seismogram:

$\begin{array}{ll}\text { New Zealand } & 20-80 \text { sec } \\ \text { Japan } & 20-80,10-80 \\ \text { Volcano Island } & 15-65,10-80 \\ \text { Mexico } & 15-65,10-60 \\ \text { Montana } & 10-60\end{array}$

dena, and azimuth of the great-circle path at Pasadena.

Figure 5 shows a record of the ground displacement (thick line) $f_{p}(\tau)$ in equation 8 , in the NS direction obtained from the pendulum seismogram of the Japan shock in 1959 and the corrected strain record (thin line), obtained by means of the technique described above. Waves having periods shorter than $10 \mathrm{sec}$ and longer than $80 \mathrm{sec}$ were cut off in the process of computation. Both records show good agreement in phase, so that the apparent phase velocity can be determined from their amplitude ratio. The ratio $f_{p}(\tau) / f_{s}(\tau)$, denoted by black dots, for each of the corresponding peaks and troughs, is high for body wave parts, such as $S, S S$, and SSS waves, and of slightly lower value for Love

waves, and it decreases further for Rayleigh waves and coda parts, except for some remarkable phases. The records of the Montana shock in 1959 , compensated in the same way, are shown in Figure 6 . In this case the amplitude ratio fluctuates in the surface wave parts. Figure 7 illustrates the corrected seismograms (N-S component) of the other three earthquakes, in which $S$ or $P S$ phases and some other surface-reflected body waves are also identified by the ratios and travel times. The mean amplitudes for each of these waves were obtained on both records by averaging the absolute amplitudes over the appropriate time interval. A correction was then applied to the respective mean amplitudes, to reduce the error that is expected to result from the approximation for the theoretical response

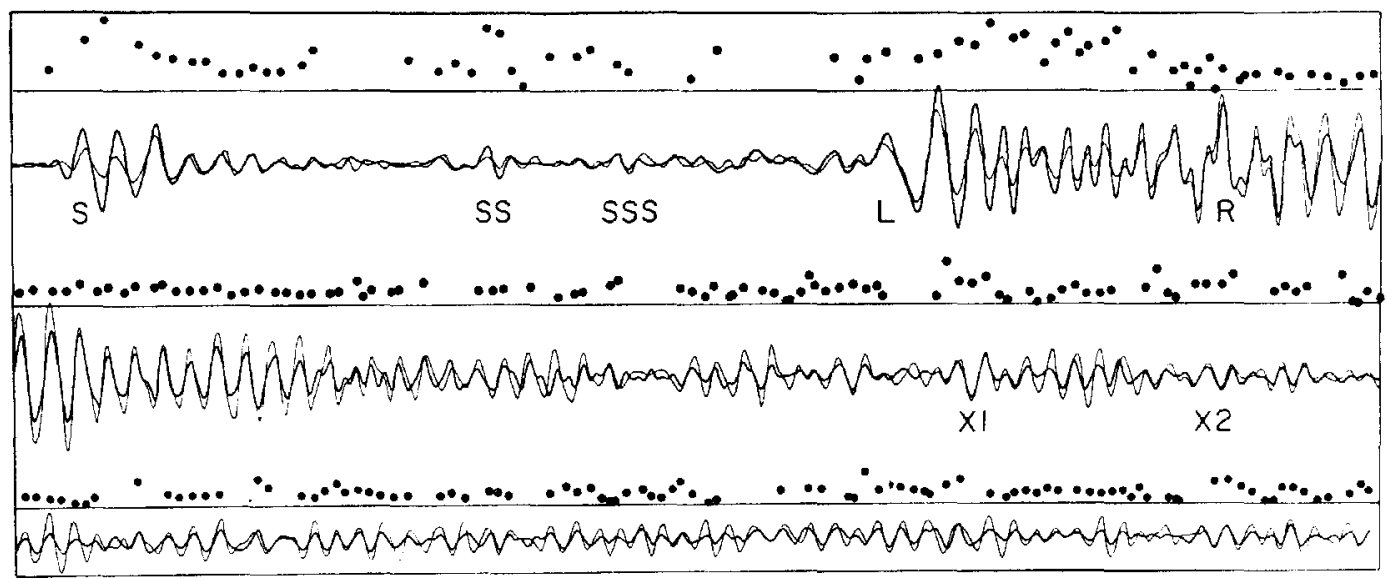

Fig. 5. Corrected pendulum and strain records and amplitude ratios for the Japan shock of Jan. 22, $1959\left(h=30 \mathrm{~km}, M=7, \Delta=76.7^{\circ}\right)$. 


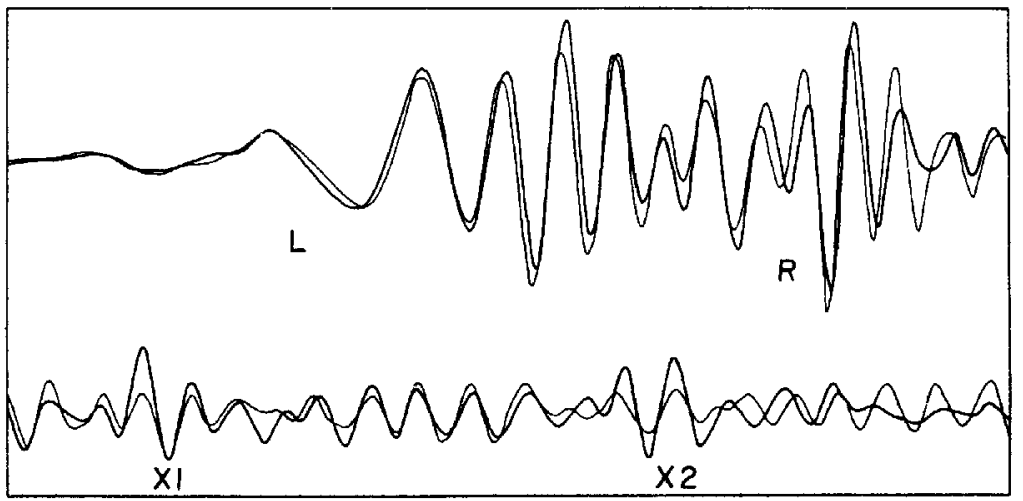

Fig. 6. Corrected pendulum and strain records and amplitude ratios for the Montana shock of Aug. 18, $1959\left(M=6, \Delta=11.8^{\circ}\right)$.

as shown in Figures 3 and 4. After the correction, the ratio of the mean amplitudes was determined using (9).

The theoretical apparent velocities of these body waves can be calculated from the JeffreysBullen table and from the direction of greatcircle path for the particular earthquake. Comparing the theoretical velocities with the observed mean amplitude ratios for twelve body wave measurements, we found a good linear relation between them (Figure 9). The instrumental constant $K$ was determined to be 3.082 $\times 10^{8}$ from this relation by the method of least squares. The determined value of $K$ is larger by about 20 per cent than that estimated roughly from the experimental data by (10), but the discrepancy is not unexpected in view of the accuracy with which the instrumental constants

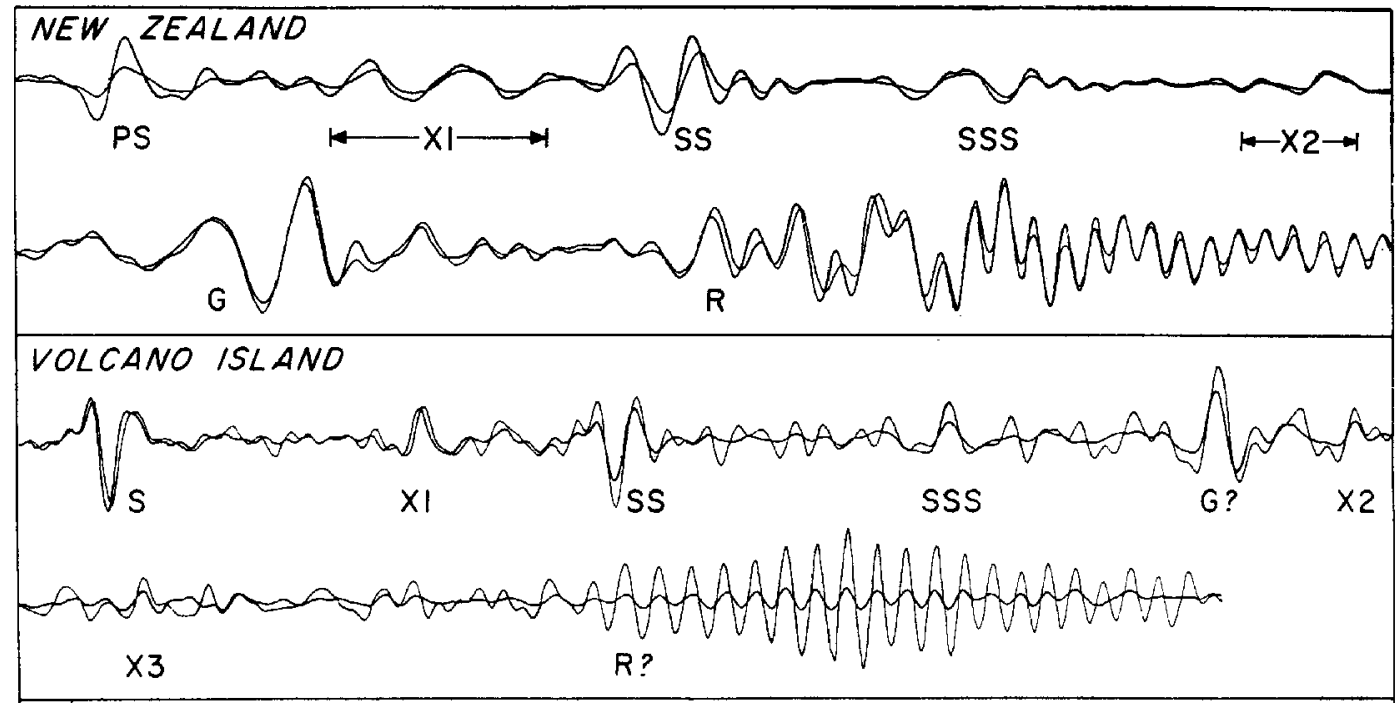

$M E \times 1 C O$

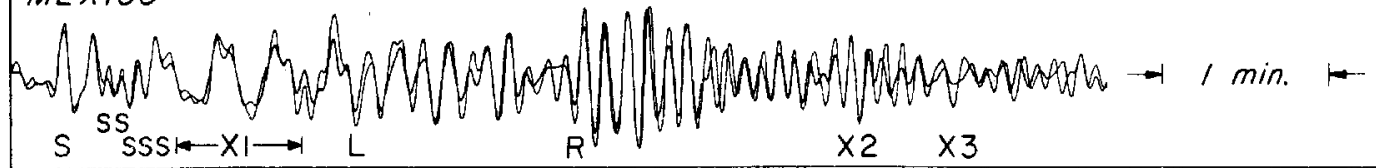

Fig. 7. Corrected pendulum and strain records for the New Zealand, Mexico, and Volcano Islands earthquakes. 
are known. This value of $K$ can be used to assign absolute values of phase velocities to the mean amplitude ratios.

The apparent phase velocities, thus determined, along the NS direction for some body waves and surface waves are tabulated in Table 2 together with their theoretically expected values. The theoretical velocities of surface waves were computed from Press' [1960] model for a continental path and from the model of Sykes et al. [1962] for an oceanic path under the as- sumption that the waves have approached the station along the great-circle path.

The local phase velocities for some of the earthquakes were determined also by a conventional station array method to compare with the results obtained by the present technique. The records of Benioff long-period vertical and horizontal seismographs at Pasadena $\left(118^{\circ} 10.3^{\prime} \mathrm{W}\right.$, $\left.34^{\circ} 08.9 \mathrm{~N}\right)$, Riverside $\left(117^{\circ} 22.5 \mathrm{~W}, 33^{\circ} 59.6^{\prime} \mathrm{N}\right)$, Barett $\left(116^{\circ} 40.3^{\prime} \mathrm{W}, 32^{\circ} 40.8^{\prime} \mathrm{N}\right)$ and Hayfield $\left(115^{\circ} 38.2^{\prime} \mathrm{W}, 33^{\circ} 42.4^{\prime} \mathrm{N}\right)$ in southern California

TABLE 2. Comparison of Theoretical and Observed Results

\begin{tabular}{|c|c|c|c|c|c|c|c|c|}
\hline \multirow[b]{2}{*}{ Shock } & \multirow[b]{2}{*}{$\begin{array}{c}\text { Type } \\
\text { of } \\
\text { Waves }\end{array}$} & \multirow[b]{2}{*}{$\begin{array}{l}\text { Travel } \\
\text { Time, } \\
\text { m s }\end{array}$} & \multirow[b]{2}{*}{$\begin{array}{l}\text { Period, } \\
\text { sec }\end{array}$} & \multirow[b]{2}{*}{$\begin{array}{l}\text { Theoretical } \\
\text { Apparent } \\
\text { Velocity, } \\
\mathrm{km} / \mathrm{sec}\end{array}$} & \multirow[b]{2}{*}{$\begin{array}{c}\text { Observed } \\
\text { Apparent } \\
\text { Velocity, } \\
\mathrm{km} / \mathrm{sec}\end{array}$} & \multicolumn{3}{|c|}{ Tripartite Results } \\
\hline & & & & & & $\begin{array}{c}\text { Apparent } \\
\text { Velocity, } \\
\mathrm{km} / \mathrm{sec}\end{array}$ & $\begin{array}{l}\text { Phase } \\
\text { Velocity, } \\
\mathrm{km} / \mathrm{sec}\end{array}$ & $\begin{array}{c}\text { Direction } \\
\text { of Wave } \\
\text { Approach, } \\
\text { deg }\end{array}$ \\
\hline \multirow[t]{6}{*}{ Montana } & $L$ & 501 & 30 & 4.63 & 5.67 & & & \\
\hline & & & 16 & 4.19 & 5.59 & & & \\
\hline & & & 12 & 3.95 & 4.82 & & & \\
\hline & & & 10 & 3.91 & 3.42 & & & \\
\hline & $R$ & 654 & 10 & 3.58 & 4.38 & & & \\
\hline & & & 8 & 3.53 & 4.23 & & & \\
\hline \multirow[t]{2}{*}{ Mexico } & $P$ & 532 & 6 & 18.23 & & 19.73 & 11.67 & 126.3 \\
\hline & $S$ & 1000 & 20 & 10.36 & 9.1 & 9.93 & 6.01 & 127.2 \\
\hline \multirow[t]{8}{*}{$\Delta=26.0^{\circ}$} & $S S$ & 1112 & 10 & 7.10 & 8.2 & & & \\
\hline & SSS & 1135 & 12 & 6.85 & 7.6 & & & \\
\hline & $L$ & 1359 & 19 & 5.87 & 5.51 & 5.25 & 3.76 & 135.8 \\
\hline & & & 16 & 5.74 & 5.55 & 5.83 & 3.71 & 129.6 \\
\hline & & & 13 & 5.61 & 5.76 & 6.73 & 3.52 & 121.5 \\
\hline & $R$ & 1619 & 16 & 5.28 & 6.66 & 5.48 & 3.49 & 129.6 \\
\hline & & & 14 & 5.22 & 6.92 & 6.51 & 3.28 & 120.3 \\
\hline & & & 12 & 5.14 & 6.02 & 7.10 & 3.18 & 116.6 \\
\hline \multirow[t]{2}{*}{ Japan } & $S$ & 2140 & 26 & 17.16 & 17.3 & 17.56 & 11.38 & 310.4 \\
\hline & $S S$ & 2638 & 20 & 12.31 & 13.1 & & & \\
\hline \multirow[t]{16}{*}{$\Delta=76.6^{\circ}$} & SSS & 2946 & 15 & 11.20 & 10.9 & & & \\
\hline & $G$ & 3818 & 37 & 7.04 & 14.0 & 9.59 & 4.49 & 297.9 \\
\hline & & & 27 & 6.81 & 14.6 & 11.33 & 4.43 & 293.0 \\
\hline & & & 20 & 6.53 & 15.6 & 13.71 & 4.35 & 288.5 \\
\hline & & & 16 & 6.35 & 14.9 & 17.30 & 4.24 & 284.2 \\
\hline & $R$ & 4203 & 32 & 6.47 & 6.86 & 7.28 & 3.90 & 302.6 \\
\hline & & & 27 & 6.35 & 6.09 & 7.50 & 3.88 & 301.2 \\
\hline & & & 24 & 6.22 & 5.92 & 7.80 & 3.86 & 299.7 \\
\hline & & & 23 & 6.17 & 5.61 & 8.18 & 3.84 & 298.0 \\
\hline & & & & & & 11.96 & 3.60 & $287.5^{*}$ \\
\hline & & & 22 & 6.10 & 6.44 & 9.20 & 3.77 & 294.2 \\
\hline & & & & & & 12.55 & 3.54 & $286.4^{*}$ \\
\hline & & & 20 & 6.02 & 6.74 & 10.07 & 3.71 & 291.8 \\
\hline & & & & & & 13.53 & 3.50 & $285.0^{*}$ \\
\hline & & & 19 & 5.97 & 5.98 & 11.64 & 3.62 & 288.1 \\
\hline & & & & & & 14.35 & 3.47 & $283.9^{*}$ \\
\hline Volcano & $S$ & 2109 & 24 & 25.34 & 25.2 & & & \\
\hline \multirow[t]{2}{*}{ Islands } & $S S$ & 2653 & 25 & 16.57 & 16.6 & & & \\
\hline & SSS & 3030 & 25 & 15.19 & 15.0 & & & \\
\hline \multirow{2}{*}{$\Delta=83.8^{\circ}$} & $G ?$ & 3329 & 33 & 9.14 & 13.9 & & & \\
\hline & & & 22 & 8.68 & 14.5 & & & \\
\hline
\end{tabular}


TABLE 2. (Continued)

\begin{tabular}{|c|c|c|c|c|c|c|c|c|}
\hline \multirow[b]{2}{*}{ Shock } & \multirow[b]{2}{*}{$\begin{array}{c}\text { Type } \\
\text { of } \\
\text { Waves }\end{array}$} & \multirow[b]{2}{*}{$\begin{array}{l}\text { Travel } \\
\text { Time, } \\
\mathrm{m} \text { s }\end{array}$} & \multirow[b]{2}{*}{$\begin{array}{l}\text { Period, } \\
\text { sec }\end{array}$} & \multirow[b]{2}{*}{$\begin{array}{c}\text { Theoretical } \\
\text { Apparent } \\
\text { Velocity, } \\
\mathrm{km} / \mathrm{sec}\end{array}$} & \multirow[b]{2}{*}{$\begin{array}{c}\text { Observed } \\
\text { Apparent } \\
\text { Velocity, } \\
\mathrm{km} / \mathrm{sec}\end{array}$} & \multicolumn{3}{|c|}{ Tripartite Resulta } \\
\hline & & & & & & $\begin{array}{c}\text { Apparent } \\
\text { Velocity, } \\
\mathrm{km} / \mathrm{sec}\end{array}$ & $\begin{array}{c}\text { Phase } \\
\text { Velocity, } \\
\mathrm{km} / \mathrm{sec}\end{array}$ & $\begin{array}{c}\text { Direction } \\
\text { of Wave } \\
\text { Approach, } \\
\text { deg }\end{array}$ \\
\hline & $R ?$ & 4155 & 25 & 8.15 & 5.39 & & & \\
\hline & & & 23 & 8.04 & 3.66 & & & \\
\hline & & & 22 & 8.00 & 4.75 & & & \\
\hline & & & 21 & 7.95 & 5.09 & & & \\
\hline & & & 20 & 7.87 & 3.69 & & & \\
\hline & & & 19 & 7.80 & 3.37 & & & \\
\hline & & & 18 & 7.78 & 3.62 & & & \\
\hline \multirow{2}{*}{ New Zealand } & $P S$ & 2905 & 50 & 15.19 & 15.4 & & & \\
\hline & $S S$ & 3515 & 43 & 10.76 & 10.5 & & & \\
\hline \multirow[t]{9}{*}{$\Delta=113.7^{\circ}$} & SSS & 3931 & 36 & 9.34 & 8.7 & & & \\
\hline & $G$ & 4459 & 80 & 5.94 & 5.96 & & & \\
\hline & & & 58 & 5.83 & 5.76 & & & \\
\hline & & & 46 & 5.76 & 5.69 & & & \\
\hline & & & 28 & 5.64 & 4.77 & & & \\
\hline & $R$ & $51 \quad 19$ & 36 & 5.21 & 6.32 & & & \\
\hline & & & 22 & 5.15 & 6.42 & & & \\
\hline & & & 20 & 5.10 & 6.03 & & & \\
\hline & & & 19 & 5.07 & 5.93 & & & \\
\hline
\end{tabular}

* Indicates the values obtained from a network of Pasadena-Barett-Hayfield. The other data were determined from Pasadena-Riverside-Barett network.

The 'apparent velocity' in this table means the apparent phase velocity along the NS direction.

were analyzed for this purpose. The results obtained for the Japan and Mexico earthquakes are also listed in Table 2, but the phase velocities of body waves other than the first $P$ and $S$ waves could not be determined by this method. As can be seen in Figure 8, the apparent phase velocities determined from the strain and pendulum records are not always consistent with the values from the station array, except for body waves. This may suggest that the former are controlled by the localized values of the velocities and the latter represent the velocities averaged over a certain area.

Discussion. Figure 9 shows a relationship between the apparent phase velocities along the NS direction as determined by the present technique and their theoretically predicted values. For body waves in the five earthquakes listed in Table 2, a good agreement was found between the two with a standard error of $0.48 \mathrm{~km} / \mathrm{sec}$ $(0.28 \mathrm{~km} / \mathrm{sec}$ without the Mexico shock), for any direction of wave approach to Pasadena. This indicates that the direction of propagation of body waves having periods longer than 10 sec did not greatly deviate from the great-circle path; hence they were not subjected to the effect of inhomogeneities of crustal structure. The tripartite results also support this fact. It may safely be said from this result that the phase velocities of body waves are expected to be determined with a probable error of 5 per cent by the present method of using the strain and pendulum seismograms.

On the other hand, the velocities obtained for surface waves do not always agree with their theoretical values. It may be that the direction of propagation of surface waves sometimes deviates from their great-circle paths owing to refraction caused by variations of crustal structure, as suggested later by some of our tripartite results. Looking at the data of Love waves for New Zealand and Mexico earthquakes and Rayleigh waves for the Japan shock, we see that the observed values agree fairly well with the theoretical. However, the somewhat scattered values in each of the wave groups do not permit us to make statements concerning dispersion of the waves. Thus there is a limit to the accuracy of the present technique when applied to surface waves. 


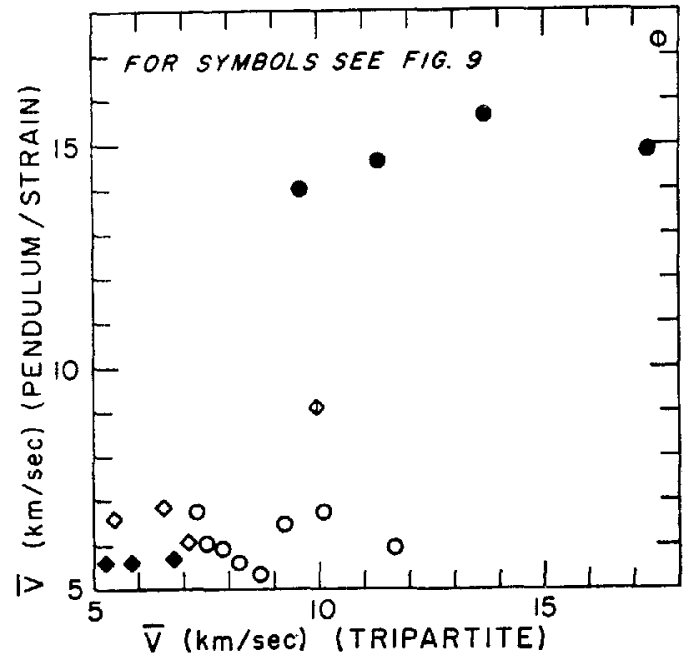

Fig. 8. Comparison of phase velocities derived from strain and pendulum records and from tripartite method.

In the Japan shock the observed velocities of Love waves are significantly higher than the theoretical. The discrepancy may be partly reconciled by taking into consideration that the waves may have been refracted at the continental boundary, assumed to lie in the direction of $\mathrm{N} 40^{\circ} \mathrm{W}$, that Press' model applies to the continent, and that Sykes' model applies to the ocean. The continental boundary, if it exists, should also give some effects on propagation of Rayleigh waves. Such refraction has been observed [Evernden, 1954; Press, 1956] and was actually ascertained by our tripartite result. However, the observed phase velocity from the strain and pendulum records shows a value consistent with waves traveling along the great-circle path. A possible explanation of this discrepancy may be that the observed velocity of Rayleigh waves at Pasadena had not yet been strongly affected by refraction.

We can find a prominent wave of $S H$ type with a large amplitude and a high group velocity $(4.6 \mathrm{~km} / \mathrm{sec}) 3$ minutes after the SSS waves on the seismogram of the Volcano Islands shock, as shown in Figure 7. There is a possibility, judging from its high group velocity, that the wave in question could be a higher mode of Love waves, because more efficient radiation may be expected of higher-mode waves than of the fundamental mode from such a deep earthquake as this shock. A theoretical study of

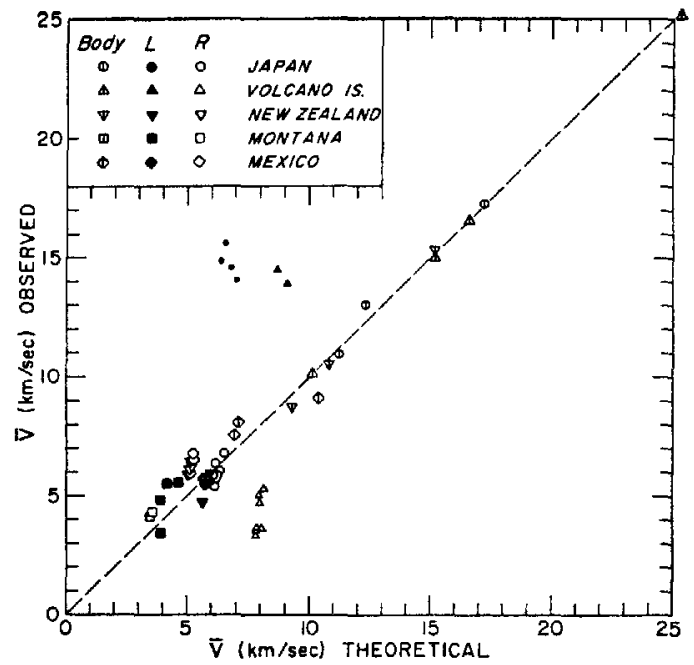

Fig. 9. Observed and theoretical apparent phase velocities.

Anderson and Toksöz [1962] shows that the group and phase velocities of the sixth-mode Love waves at a period of $30 \mathrm{sec}$ have velocities of nearly 4.6 and $6.2 \mathrm{~km} / \mathrm{sec}$, respectively, for CIT 6 oceanic structure. The observed values for both the velocities seem to be consistent with this interpretation. The effect of the continental boundary may probably be neglected for these higher-mode waves, as their properties should primarily be influenced by the upper mantle.

The observed phase velocities of Rayleigh waves from the same shock are much lower than the theoretical values for the fundamental mode. Theoretically, it is unlikely that the fundamental mode of Rayleigh waves is generated from an earthquake of such great focal depth. However the Rayleigh waves cannot be a higher mode, because of their observed low velocities. Consequently, these waves may be considered as Rayleigh waves converted near the epicenter from some other kind of waves, as the observed arrival times indicate that the waves have traveled as Rayleigh waves almost over the entire path.

It was found that our method up to this point can be effectively used to estimate the apparent velocity of body waves and may also be applied to the identification of higher modes of surface waves. It would therefore be possible to pick many of the unidentified phases on a seismogram by this technique. 
TABLE 3. Remarkable Phases

\begin{tabular}{|c|c|c|c|c|c|c|c|}
\hline \multirow[b]{2}{*}{ Shock } & \multirow[b]{2}{*}{ Phase } & \multirow[b]{2}{*}{$\begin{array}{c}\text { Travel } \\
\text { Time }\end{array}$} & \multirow[b]{2}{*}{$\begin{array}{c}\text { Period, } \\
\text { sec }\end{array}$} & \multirow[b]{2}{*}{$\begin{array}{l}\text { Observed } \\
\text { Apparent } \\
\text { Phase } \\
\text { Velocity, } \\
\mathrm{km} / \mathrm{sec}\end{array}$} & \multirow[b]{2}{*}{$\begin{array}{l}\text { Expected } \\
\text { Phase } \\
\text { Velocity, } \\
\mathrm{km} / \mathrm{sec}\end{array}$} & \multicolumn{2}{|c|}{ Identification } \\
\hline & & & & & & Phase & $\begin{array}{c}\text { Observed } \\
\text { Phase } \\
\text { Velocity, } \\
\text { km/sec }\end{array}$ \\
\hline \multirow[t]{2}{*}{ Montana } & $X 1$ & 812 & 10 & 7.48 & 6.86 & & \\
\hline & $X 2$ & 959 & 10 & 6.46 & 5.93 & & \\
\hline \multirow[t]{5}{*}{ Mexico } & $X 1$ & 1152 & 40 & 6.26 & 4.08 & & \\
\hline & $X 2$ & 1908 & 12 & 6.98 & 4.55 & & \\
\hline & $\bar{X} 3$ & 2041 & 16 & 15.09 & 9.83 & & \\
\hline & $X 1$ & $49 \quad 10$ & 27 & 9.52 & 5.65 & & \\
\hline & $X 2$ & 5204 & 24 & 8.25 & 4.90 & & \\
\hline \multirow[t]{3}{*}{ alcano Islands } & $X 1$ & 2427 & 32 & 22.45 & 10.19 & $s S$ & 10.10 \\
\hline & $X 2$ & 3531 & 20 & 12.45 & 5.65 & & \\
\hline & $X 3$ & $\begin{array}{ll}37 & 13\end{array}$ & 24 & 16.93 & 7.68 & & \\
\hline \multirow{2}{*}{ Jew Zealand } & $X 1$ & 3143 & 64 & 10.20 & 7.97 & & \\
\hline & $X 2$ & 4209 & 46 & 8.88 & 6.94 & SSSS & 6.84 \\
\hline
\end{tabular}

Some remarkable phases can be detected on the seismograms of the aforementioned five earthquakes. Table 3 summarizes these phases with their travel times, periods, and apparent velocities along the NS direction as obtained by the present method and the true phase velocities that are expected. The phase denoted by $X 1$ in the Volcano Islands shock is rather difficult to identify from the groups $p S c S, s S$, and $s S c S$ solely on the basis of travel time. The theoretical apparent velocities of these waves are 12.75, 10.10 , and $12.61 \mathrm{~km} / \mathrm{sec}$, respectively. Our method gave a value of $10.19 \mathrm{~km} / \mathrm{sec}$ for the wave, which must therefore be identified as $s S$. The travel-time difference between $s S$ and $S$ will be useful for an accurate determination of the focal depth. The observed apparent velocity together with the travel time can identify the phase $X 2$ in the New Zealand earthquake. It must be the shear wave reflected four times at the earth's surface, namely SSSS. Most of the other phases have not yet been identified. But among them, the long-period waves $X 1$ in the New Zealand and Mexico earthquakes, and a clear body wave $X 1$ with a large travel time in the Japan shock, seem worthy of further investigation. Better results might be expected for longer-period surface waves that are less sensitive to structural variations along the propagation paths.

The method could be considerably improved if two horizontal components of the strain and pendulum seismographs were used together and if calibration curves were more precisely known.

Acknowledgments. Our thanks are due Dr. Frank Press, Dr. Hugo Benioff, and Dr. Charles F. Richter for their kind advice in the present study. We are also grateful to Dr. Michael Shimshoni, Dr. Shelton Alexander, and Mr. Ivar Sedleniek for their helpful discussions. Dr. Nafi Toksöz and Dr. Lynn R. Sykes kindly read the manuscript and made valuable suggestions.

This research was supported by grant AFAFOSR-25-63 of the Air Force Office of Scientific Research as part of the Advanced Research Projects Agency project Vela.

\section{REFERENCES}

Aki, K., Study of earthquake mechanism by a method of phase equalization applied to Rayleigh and Love waves, $j$. Geophys. Res., 65, 729$740,1960$.

Anderson, D. L., and M. N. Toksöz, Surface waves on a spherical earth, J. Geophys. Res., $68,3483-$ $3500,1963$.

Benioff, H., A linear strain seismograph, Bull. Seismol. Soc. Am., 25, 283-309, 1935.

Benioff, H., and B. Gutenberg, The response of strain and pendulum seismographs to surface waves, Bull. Seismol. Soc. Am., 48, 229-237, 1952.

Brune, J., J. Nafe, and J. Oliver, A simplified method for the analysis and synthesis of dispersed wave trains, J. Geophys. Res., 65, 287-304, 1960.

Evernden, J. F., Direction of approach of Rayleigh waves and related problems, Bull. Seismol. Soc. Am., 44, 159-184, 1954.

Mikumo, T., Notes on seismograph feedback systems, in Geophysical Papers Dedicated to Pro- 
fessor K. Sassa, pp. 271-276, Kyoto University, Kyoto, Japan, 1963.

Press, F., Determination of crustal structure from phase velocity of Rayleigh waves, 1, Southern California, Bull. Geol. Soc. Am., 67, 1647-1658, 1956.

Press, F., Crustal structure in the CaliforniaNevada region, J. Geophys. Res., 65, 1039-1051, 1960.

Satô, Y., Attenuation, dispersion and the wave guide of the $G$ waves, Bull. Seismol. Soc. Am., 48, 231-251, 1958.

Sykes, L., M. Landisman, and Y. Satô, Mantle shear velocities determined from oceanic Love and Rayleigh wave dispersion, J. Geophys. Res., 67, 5257-5271, 1962.

Toksöz, M. N., and A. Ben-Menahem, Velocities of mantle Love and Rayleigh waves over multiple paths, Bull. Seismol. Soc. Am., 58, 741-764, 1963.

Tukey, J., Equalization and pulse shaping techniques applied to the determination of initial sense of Rayleigh waves, Report on a Panel of Seismic Improvement, Apperdix 9, 1959.

(Manuscript received October 23, 1963; revised November 20,1963 .) 